\title{
Mulheres Especialmente Marginalizadas: Uma Entrevista com Dolores Juliano
}

\section{Juliana Przybysz}

Universidade Estadual de Ponta Grossa / Grupo de Estudos Territoriais, Brasil

juliana.przybysz@gmail.com

As discussões sobre gênero e sexualidade estão presentes nas mais variadas ciências sociais e humanas. A abordagem das sexualidades ainda se coloca como um tema árduo para o campo do feminismo, notadamente no que diz respeito ao tema do trabalho sexual, prostituição feminina ou qualquer outra forma de nomear a troca de relações sexuais por vantagens econômicas. As feministas estão longe de alcançar consenso em torno deste tema que se mescla com aspectos de vulnerabilidade econômica, nacionalidade, cidadania e saúde.

A pedagoga e antropóloga Dolores Juliano é um dos mais importantes nomes contemporâneos da discussão sobre gênero e sexualidades. Nascida em Necochea, na Argentina, começou sua carreira na Pedagogia e mais tarde se licenciou em Antropologia na Universidade de Mar del Plata. Com a ditadura militar na Argentina mudou-se para Barcelona, onde reside desde 1977 e onde iniciou sua carreira na docência universitária. Já com doutorado em Antropologia na Universidade de Barcelona, foi professora titular nesta mesma instituição até sua aposentadoria, em 2001. Sua trajetória acadêmica está marcada pela sua vivência como mulher, imigrante e feminista, trazendo para o debate em torno das relações de gênero e sexualidades aspectos como luta, resistência e estigma. Um pouco da vivência desta brilhante intelectual e ativa feminista está apresentada nas páginas que se seguem, a fim de servir de inspiração para todxs nós.

Juliana Przybysz: Sua trajetória como pesquisadora tem se voltado, sobretudo, nas questões de gênero, na maioria das vezes ligadas aos coletivos de minorias como é o caso das prostitutas, imigrantes, minorias éticas, dentre outros. Como foi sua trajetória acadêmica e quais os motivos que te levaram a se aproximar destas temáticas?

Dolores Juliano: $\mathrm{Eu}$ sou antropóloga e, do ponto de vista da antropologia, me importo muito como se estruturam as relações sociais. Dentro da antropologia sempre me interessou ver como as diversas sociedades atribuem a homens e mulheres condutas diferentes. Estas condutas diferentes não são as mesmas em todas as sociedades, ou seja, não correspondem a características biológicas, mas correspondem simplesmente a construções culturais. Uma vez que se realizam, estas construções se naturalizam. Então, toda a sociedade pensa que suas relações internas e, entre elas, os modelos de gênero, são normais, naturais, não necessitam ser questionados porque não se desprendem da natureza quando, na realidade, em todos os casos são arbitrários culturais, são construções. Nas distintas culturas atribuem a homens e mulheres tarefas diferentes. Por exemplo, em muitas culturas é próprio das mulheres tudo o que é relacionado com a vestimenta ou com a arte e, em outras culturas, isto pode estar atribuído aos homens. Neste momento em Madrid, por exemplo, estão os homens costurando em máquinas e estas coisas te provam que tem muito pouco a ver com a natureza. Então, este foi um tema que me interessou muito trabalhar. Outro aspecto que me interessou estudar é como as tarefas destinadas a homens e mulheres podem ter efeitos distintos e o que têm em comum nas distintas culturas. Não é em todas as culturas, mas a maioria delas é que atribuí maior mérito, maior poder, maior prestigio às 
tarefas destinadas a homens que a mulheres. Com isto podemos ver em nossas próprias culturas que os homens recebem por seus trabalhos mais dinheiro que as mulheres, pois se consideram especializados os trabalhos masculinos e não os femininos. Mesmo quando um trabalho tem certa característica de mudança de gênero, se feminiza ou se masculiniza, então passa a ter característica de prestigio destinado ao gênero que predomina nele, como, por exemplo, o magistério. Quando era exercido fundamentalmente por homens tinha determinado prestígio social, quando se feminiza tem menos prestígio ou o trabalho nas bibliotecas ou qualquer outro trabalho. Mas, por que aderem esta conotação diferente? Este é um ponto que tem me interessado muito e, na medida em que as mulheres são um setor da sociedade, tradicionalmente desvalorizado, em nossa cultura me interessou também o que tem passado. Interessou-me saber como as mulheres transgressoras, que fazem o uso autônomo de sua sexualidade ou que infringem algumas das leis da sociedade são tratadas. Também trabalhei com mulheres presas, mulheres delinquentes, mulheres imigrantes. $\mathrm{Ou}$ seja, mulheres que transgridem o papel de gênero. Em geral, trabalhei com mulheres que, além da desvalorização global que sofrem apenas por serem mulheres, também sofrem dificuldades econômicas e fazem parte de um setor especialmente desvalorizado.

J.P.: Outra vertente de sua trajetória está relacionada com a educação, com ênfase em gênero. Os livros 'Educación Intercultural: Escolarización y minorías étnicas (1993) e Enseñar Ciencias Sociales desde valores no-androcéntricos' (1999) são exemplos disso. Como avalia que a educação com enfoque de gênero pode contribuir para justiça social?
D.J.: $\mathrm{Na}$ realidade, a pergunta deveria estar invertida, porque minha primeira licenciatura é em Pedagogia. Eu venho do mundo da pedagogia. Então, a pergunta seria por que antropologia? A antropologia foi uma segunda opção. Posso te explicar. Porque na Pedagogia nos davam as ferramentas para atuar sobre as pessoas, modificar sua conduta e educação. Você toma um conjunto de pessoa e através do sistema educativo modifica algumas de suas condutas e na Pedagogia ensinavam como fazê-lo, mas não ensinavam por que fazê-lo. Então, para desenvolver a teoria pedagógica me parece que faz falta um marco de interpretação mais amplo. Assim eu o busquei nas ciências sociais. A antropologia foi o resultado de um passo a mais no campo da educação. Uma vez marcado isso, utilizando os conhecimentos antropológicos no campo da educação e de alguma maneira utilizando os conhecimentos pedagógicos no campo da antropologia, me resultou de muita utilidade. O tema central de meu interesse não mudou porque é de alguma maneira a desigualdade social. Se nós vamos falar da desigualdade social e de como superá-la, isso é um problema de muitos pedagogos. Estou pensando em toda a escola de Paulo Freire na verdade. Na luta contra a desigualdade social, não tem como não focar no ponto de vista de uma desigualdade mais estendida. Creio que não se pode separar a educação da luta pela transformação e, assim, discutir as classes em uma sociedade desigual, mas também as desigualdades de gênero que, por conseguinte, merecem atenção teórica. Podese dizer que a sociedade está fazendo isso em todas as disciplinas, como o marco feito vocês, uma revista com estudos geográficos e de gênero. 
J.P.: Em seu texto 'Mujer y familia em España y América' publicado no livro 'Antropologia - Una exploración de la diversidade humana' há a insistência no argumento de que mesmo com a reestruturação familiar a partir da revolução industrial ainda se mantém os referentes simbólicos da família tradicional para assegurar a tranquilidade da sociedade. Por que tem sido importante para sua trajetória acadêmica colocar em evidência os modelos e práticas familiares?

D.J.: Há uma ideia muito generalizada e muito injusta que diz que se os meninos e os homens são machistas e discriminam as mulheres é culpa das mães. Porque as mães foram aquelas pessoas que os ensinaram. Isso é absolutamente injusto. Mas isso é uma demonstração de que a família é considerada de pequena importância e que dentro da família a mãe ensina a manter os papéis tradicionais. Evidentemente não é verdade que as mães ensinam os meninos a ser machistas. As mães normalmente dão educação mais igualitária que podem ou que sabem. O que passa é que nem sempre se animam a romper com todas as normas e todas as diretrizes, entre outras coisas, por temor de prejudicar os meninos, caso eles não se encaixem aos modelos masculinos. Mas onde os meninos geralmente aprendem discriminação? É nos mesmos lugares onde aprendem violência e agressividade. Ou seja, em um grupo de pares, na relação com a sociedade, a partir de modelos masculinos. É daí que identificam como são os homens e não a partir dos conselhos da mãe. A ideia é que a sociedade controla os indivíduos a partir de dois tipos de recursos. As pressões informais e as sanções formais. Os controles informais são também muito eficientes e não é necessário colocar os controles legais. Os controles informais que fazem parte da tradição e dos costumes são normalmente muito conservadores, são muito conservadores e tendem a transmitir de uma geração a outra por múltiplas vias e não somente pelo ensino que queira fazer uma mãe. São múltiplas as vias possíveis de identificação. Os papéis tradicionais não correspondem com nenhum tipo de necessidade biológica, não correspondem com a natureza humana, são modificações culturais que criam condutas possíveis. Todos nós somos seres humanos capazes de qualquer tipo de conduta como as de cuidado, de agressividade, de egoísmo, de generosidade. Enfim, podemos ter uma grande variedade de condutas. Quando socialmente nos atribuem um conjunto de condutas, a meninos algumas e meninas outras condutas, o que passa é que quando correspondemos à elas ganhamos prêmios $\mathrm{e}$ quando não correspondemos somos castigados. Há um reconhecimento de 'boa garota', 'simpática', 'a mãe estará orgulhosa de sua filha' e isso é recompensado. Quando se pensa 'esta menina é um pouco estranha', é porque não corresponde ao esperado. Mas isso não deveria ser importante. Então são essas expectativas de condutas que nos limitam, homens e mulheres a desempenhar papéis de gênero. Nós mulheres temos que ser doces, amáveis e temos o encargo do cuidado dos demais. Os meninos tem que ser agressivos, egoístas e levar o mundo para frente. Não são todas as meninas e meninos que seguem este modelo. Mas para quem se distancia destes modelos há castigos sociais, sanções. Além disso, manter os papéis permite à pessoa viver com menos conflitos. Há uma grande quantidade de pessoas que se adéquam aos papéis ou fingem que se adéquam como uma forma de sobreviver em uma sociedade agressiva e competitiva como a nossa. Isto acaba fazendo com que se mantenha uma espécie de acordo em que os papéis de gênero se mantenham. Um exemplo mínimo sobre o assunto seria as 
cores a serem utilizadas para crianças recémnascidas, o rosa e o azul. Não é que as pessoas considerem que isto é importante ou que custaria muito mudar isto. Mas é difícil. É difícil porque imediatamente teria que estar explicando porque mudou a cor e teria que superar as dificuldades para poder diferenciar se a criança é um menino ou uma menina. Então geraria uma série de pequenos problemas e para evitar estes pequenos problemas, se segue com o modelo. Como se segue com o modelo, todo mundo está de acordo, mas é um falso consenso, não?

J.P.: Em seu artigo 'El mito del instinto maternal' publicado em 'Mujeres y Salud' (2003), argumenta que pensar a conduta das mulheres como algo natural é evitar as discussões sobre o papel das mulheres na sociedade e que um dos âmbitos mais eficazes para isso é colocar a maternidade como um instituo natural da mulher. Como estas discussões sobre maternidade e maternagem tem embasado as suas discussões sobre gênero ligadas às minorias?

D.J.: A reprodução faz parte de um instinto de sobrevivência da espécie que se dá em homens e mulheres que desejam e gostam de crianças. Agora, evidentemente a maternidade tem um custo biológico e social maior que a paternidade. Por conseguinte, é normal que as mulheres pensem mais que os homens no momento de assumir um compromisso deste tipo, que as comprometem durante muitos anos, tanto fisicamente pelo tema da gravidez, do parto, da dor, de risco e depois no tema do cuidado e da atenção. Nestas condições seria normal na sociedade que se considere que as mulheres, frequentemente, sejam bastante reticentes a tendência de maternidade. Que as mulheres tenham a intenção de postergar a maternidade ou, inclusive considerar não ter filhos, quando consideram o que significa para uma mulher a maternidade em nossa sociedade. Mas, no entanto, a sociedade parte da ideia de que a maternidade é consubstancial à vida das mulheres e que uma mulher não está completa até que seja mãe. Em muitos países a pressão social é bastante forte. Se a mulher disser 'eu não estou especialmente interessada neste projeto de maternidade' então as pessoas imaginam que há algum problema com ela. Se isolarmos a gravidez, o parto e a amamentação com leite materno, todos os demais trabalhos relacionados à maternidade são socialmente atribuídos. Os encargos são atribuídos às mulheres, mas poderia ser à qualquer pessoa. Tais tarefas ocupam muito tempo, esforço, desgaste físico e emocional. Não podemos considerar a maternidade como uma aspiração universal a todas as mulheres de todos os lugares e épocas. No entanto, o modelo de feminilidade está estreitamente ligado com o modelo de maternidade. Não somente se considera que este modelo é natural, mas que todas as obrigações que advém dele é uma tarefa feminina. Por exemplo, a maternidade em qualquer espécie animal dura um período de dependência física e logo estes laços se dissolvem. Mas no caso dos seres humanos, a maternidade é eterna. Podem os filhos ter cinquenta ou sessenta anos, mas tem direito às prestações maternas. Mais ainda, isso pode passar de uma geração a outra. Uma mulher jovem pode dizer 'bom eu não estou em condições de ter filhos porque eu não posso cuidar, mas eu o passo à minha mãe', então como é avó, então ela estará a cargo de exercer a maternidade pela filha. Neste sentido, se passa todas as tarefas maternas às avós o que é muito, muito frequente. A maternidade beneficia também aos homens. Por exemplo, um homem mais velho, um companheiro, um marido pode exigir da esposa os mesmo cuidados ou atenção que recebia da mãe, como o preparo 
da comida, o cuidado com a roupa, com sua saúde, como se fosse uma eterna criança. Afinal, se entende que se ela é uma boa mulher e se está apaixonada, então atenderá, cuidará, se encarregará dele. O homem seria, por definição, um ser adulto que teria que cuidar de si mesmo. No entanto, a derivação da maternidade resulta cômoda aos homens. $\mathrm{O}$ cuidado que as mulheres dispensam cuidado de tarefas para um ser adulto que deveria cuidar de si mesmo libera-os para outras ações. Nestas condições o tema da maternidade está muito relacionado com os modelos de gênero e atua perversamente quando nos referimos aos setores mais feminilizados das sociedades, com muita frequência, quando falamos dos setores discriminados da sociedade. Estou pensando sempre no modelo de trabalho sexual porque este é o setor com maior carga de estigma social, pois se relacionam a uma conduta na qual a sexualidade é algo que se vende, não algo que se presenteia e que está ligada ao cuidado. A relação sexual que é paga é um contrato por tempo limitado, é o uso autônomo da sexualidade que é entendida como sendo realizada por uma mulher que não está cumprindo bem seus papéis de gênero. Por consequência, estas mulheres são vistas como não sendo boas mães e em muitos casos, elas são castigadas pela transgressão e lhes retiram, como castigo, o direito de se relacionar com os filhos. As mulheres presas também perdem com frequência a guarda dos seus filhos. Há estudos na União Europeia, onde $12 \%$ das presas perdem a guarda dos seus filhos e isso é uma quantidade muito alta, sobretudo levando em conta que os homens, não me recordo exatamente muito bem, mas creio que em apenas 3 ou $4 \%$ perdem a guarda de seus filhos quando estão presos. As prostitutas, com muita frequência, também perdem a guarda dos filhos e as crianças são colocadas para adoção. Algumas crianças que se adotavam em Marrocos, por exemplo, não eram crianças abandonadas, mas filhos de prostitutas. Agora não mais porque isto está prescrito. Esta situação é um equívoco, já que uma coisa não tem nada haver com a outra. Estas mulheres prostitutas em Marrocos podiam até não cumprir seu papel de gênero em matéria de sexualidade. Mas poderiam ser excelentes mães. Além disso, é particularmente injusto, já que muitas mulheres que delinquem ou que se dedicam a atividades tão estigmatizadas como a prostituição, o fazem porque tem a responsabilidade de manter os filhos sozinhas, sem apoio familiar, sem apoio social, sem uma formação ou trabalho reconhecido como válido ou bem pago. Elas se encontram em um dilema, pois para seguir adiante educando os filhos, frequentemente tem que optar por estes caminhos. Quando entram no trabalho sexual para manter os filhos, acabam por perdê-los. $\mathrm{O}$ caso de muitas mulheres presas é o mesmo.

J.P.: Uma linha de estudos importante na sua trajetória é relacionada a temática de sexualidade e prostituição /ou trabalho sexual. Como resultado disso tem vários livros publicados como 'La prostitución: el espejo oscuro' (2001), 'La prostitución a debate: por los derechos de las prostitutas' (2007). Há também inúmeros capítulos de livros e também artigos científicos com esta temática. Como este tema passou a fazer parte de seu interesse científico? Como o meio acadêmico reagiu ao seu trabalho?

D.J.: Esta abordagem começou a partir do tema da discriminação. O que me interessava basicamente era como se construía socialmente as teorias de estigmatização. Então isso me levou forçosamente para analisar o trabalho sexual porque ele sofre imensa estigmatização. Foi por isso que o 
tema me interessou. Vivemos em uma época em que 'teoricamente' se mostra uma liberdade sexual e ninguém seria estigmatizado por manter várias relações sexuais. Atualmente se considera normal que homens e mulheres não valorizem mais a virgindade e que passem a ter relações sexuais estáveis e também instáveis. Logo, manter várias relações sexuais não é vergonha para ninguém e isso seria motivo para sancionar ninguém. Mas vivemos em uma economia de mercado em uma sociedade capitalista na qual se considera que praticamente todas as atividades podem ser compradas e vendidas. Vivemos em um mundo onde o próprio conhecimento é assim. Se vamos dar uma conferência ou publicar um artigo querem que paguem. $\mathrm{E}$ isso, não tira, mas agrega valor a conferência ou ao trabalho. Considera-se que qualquer atividade pode ser cobrada. Então, partindo destas bases, que problema há que uma pessoa decida ter relações sexuais e possa cobrar por elas. Onde está o problema? Mas o problema existe porque quando unimos sexualidade e capitalismo isso explode nas nossas mãos. A estigmatização da prostituição é grande e acho, inclusive, que ela está aumentando com o passar dos anos. Qual é a razão disso? A sociedade crê que está julgando algo importante. Mas o que ela julga tem muito pouco haver com quem são ou o que fazem as prostitutas. Afinal elas não são tantas nem tão importantes socialmente para dedicar a elas tanto esforço de estigmatização. Elas vivem em seu mundo e o que para mim é curioso é a razão de não as deixamos viver em seu mundo tranquilamente. A conclusão a que se pode chegar é que o que está em jogo é precisamente o modelo de gênero tradicional. A estigmatização das prostitutas é uma mensagem social para as mulheres não prostitutas e fundamentalmente para as mulheres jovens. Veja, os modelos de gênero são algo incômodo que pede muito ás mulheres e retribui muito pouco à elas. $\mathrm{O}$ modelo ideal exige das mulheres muito sacrifício, muitas postergações e se dá pouco reconhecimento social. Mas a sociedade quer assegurar que se a mulher não atender a isso vai ser muito pior para ela. Se não é uma boa menina, te tomarão por uma má menina e uma má menina é sinônimo de uma prostituta e que terá estigmatização mais absoluta. A estigmatização do trabalho sexual é uma medida de controle social dirigida não tanto às prostitutas, mais $\operatorname{sim}$ ao resto das mulheres. Por isso eu creio que é muito importante trabalhar este tema. Porque não é uma luta em defesa de uma minoria, mas é fundamentalmente uma forma de se colocar em defesa que todos os seres humanos. Temos de viver a nossa sexualidade como queremos e isto somente se pode conseguir se levantamos o problema da estigmatização dos setores mais estigmatizados. Agora, como se toma este tipo de trabalho no ponto de vista da academia. Bom, do ponto de vista da academia, no mundo da antropologia já se sabe que sempre estamos trabalhando com grupos ou setores que são vulnerabilizados. Não assombra ninguém na antropologia se fale de trabalho sexual, como de qualquer outra minoria. Isto desde o ponto de vista acadêmico não há problema. Não é um tema que se tenha um grande reconhecimento, mas é um tema que se pode trabalhar como qualquer outro. Curiosamente, o mais difícil de trabalhar este tema é com determinados setores do feminismo. $\mathrm{O}$ feminismo que tem uma tradição muito puritana, fundamentalmente o feminismo mais institucional, de tradição ocidental. A vertente que revindicava os direitos da mulher, o direito ao voto, a partir da superioridade moral das mulheres tem uma verdadeira dificuldade para incorporar em seu discurso a mulher delinquente, a mulher transgressora, a prostituta, as lésbicas e as 
trans. Tem sido muito difícil o reconhecimento das reivindicações destes setores dentro das correntes predominantes do feminismo. No caso das prostitutas, tem resultado muito mais fácil concebê-las como vítimas do que como agentes de sua própria decisão. Não estou dizendo com isso que não há prostituição forçada, que não há delitos dentro do mundo da prostituição ou que não há vítimas. Sim, há, mas tem também muitas outras atividades de outros âmbitos também. Em qualquer outra atividade que envolve dinheiro e a prostituição envolve dinheiro e, sobretudo, se esta atividade não está regulada pela lei, podem entrar delinquentes, pode haver abusos e de fato há. Mas também não estou dizendo que haja em todas as situações de prostituição. O que passa é que eu e muitas outras pessoas que trabalhamos no ponto de vista dos direitos das trabalhadoras sexuais pensamos que a melhor maneira de combater os delitos que se comentem no campo do trabalho sexual é dando às prostitutas um âmbito legal, no qual podem se defender, reconhecer seus direitos de realizar esta atividade ou a que queiram. Reconhecer, sobretudo, a validade dos seus depoimentos e considerá-las pessoas com capacidade de decisão e, por consequência, também com capacidade de defesa e apoiar suas revindicações. Se for ao contrário, se usa a perspectiva de considerar que todo o âmbito da prostituição é delito e que todas as prostitutas são vitimas. Quando se recorre à proibição da prostituição, acabamos por deixar as prostitutas indefesas, já que elas não podem acusar ninguém de ter atentado contra seus direitos, sua liberdade, pois a atividade que desenvolvem é considerada criminosa. Então, com a ideia ou com o discurso de proteger as vítimas, realmente o que se faz é aumentar seu desamparo.
J.P.: A prostituição tem sido um tema tratado com frequência dentro do movimento feminista. As discussões são polêmicas e isso foi evidenciado no seu artigo 'El trabajo sexual en la mira: polemicas y estereotipos' (2005). Como se estabelece sua posição diante das polêmicas feministas sobre prostituição?

D.J.: $\mathrm{Eu}$ creio que a existência destas posições irredutíveis ocorre porque as pessoas que são abolicionistas não aceitam discursos intermediários. Deve-se ter em conta a diferença entre as mulheres que são legais e as imigrantes ilegais, as menores de idade e as adultas. Há uma série de diferenças a serem consideradas, não se pode colocar tudo no mesmo saco. Fundamentalmente, tem que se fazer uma distinção importante entre a prostituição voluntária, como uma opção laboral e a prostituição forçada. São duas coisas completamente diferentes. Então o fato de que o debate seja tão duro e acalorado impede dedicar tempo e esforço para melhorar as condições de vida das pessoas que estão no trabalho sexual. As pessoas que consideram a prostituição um mal social (nunca sei muito bem o que parece um mal, se é o fato da sexualidade em si mesma ou o fato de comprar ou vender a atividade) omitem a situação real dessas mulheres. Ora, se a prostituição é um mal intolerável, é muito fácil vencer boa parte dela. Melhoremos as condições laborais das mulheres em geral, paguemos melhor o trabalho doméstico, o cuidado de idosos, o cuidado dos enfermos, pois estas são as atividades alternativas que podem dedicar as pessoas que desenvolvem o trabalho sexual. Se todas estas atividades estiverem muito bem pagas, as mulheres realmente poderiam optar mais facilmente por não exercer a prostituição. $\mathrm{Na}$ atualidade estão pedindo às mulheres que abandonem o trabalho sexual e que se dediquem às tarefas pelas quais 
ganham um terço do que ganhavam na prostituição. Isto não é uma grande oferta. Então, eu creio que uma melhora geral das condições laborais das mulheres permitiria que outras soluções laborais sejam mais atrativas economicamente e que as mulheres que realmente não querem se dedicar ao trabalho sexual possam dedicar-se a outras atividade. Entretanto, se as opções são tão pobres economicamente há muitas mulheres que preferem não se dedicar a outra tarefa mais agradável e mais fácil que o trabalho sexual, mas o seguem fazendo simplesmente porque necessitam de dinheiro.

J.P.: Na maioria dos seus trabalhos, como, por exemplo, em seu livro 'El espejo oscuro: la prostitución' (2001) você defende que se escute a voz das prostitutas e de mulheres que são estigmatizadas e que não se deve falar por elas. Pode comentar um pouco sobre esta afirmação que é tão presente em seus trabalhos, discussões e aportes teóricos?

D.J.: Quando nós começamos investigar o tema de trabalho sexual já partimos de uma ideia bastante clara. Nosso grupo de trabalho se chama LICITS - Linha de Investigação e Cooperação com Imigrantes e Trabalhadoras Sexuais. Partimos da ideia de que teria que ser um trabalho de investigação plural. Havia antropólogas, psicólogas, sociólogas e trabalhadoras sexuais e decidimos que trabalharíamos juntas para ver quais eram as reivindicações, o que elas pediam, qual era sua voz referente aos problemas que enfrentavam. Isso parece normal, ou seja, não é algo estranho trabalhar um tema junto com as pessoas que vivem o tema diariamente. Mas isso é pouco entendido ainda. Quando me convidaram, como antropóloga, para participar de uma discussão de planejamento de uma das muitas leis que discute sobre o trabalho sexual, eu disse: 'mas eu formo parte de uma equipe de trabalho, então teria que ir com algum outro membro de minha equipe de trabalho'. Disseram-me 'sim, sim, não tem problema'. Para mim era claro que a pessoa a ir participar deveria ser uma trabalhadora sexual. Convidei uma pessoa que trabalhava no grupo e ela aceitou. Quando me pediram os nomes e eu os dei e me perguntaram: 'e a outra companheira quem é? O que é profissionalmente?' Respondi: 'Pois é uma trabalhadora sexual'. Foi um silêncio no outro lado da linha e a pessoa disse: 'agora as chamam assim?' Então, se vão discutir o tema de trabalho sexual, o mínimo que se pode fazer é ter a participação de uma trabalhadora sexual discutindo este tema, não é verdade? Enfim, finalmente a colocaram no convite como acompanhante e não colocaram a atividade, que era trabalhadora sexual. Há uma imensa dificuldade da sociedade em reconhecer que elas tem um discurso próprio. Felizmente, nos últimos anos, ela tem tido mais voz. No Brasil é conhecido o caso de Gabriela Leite, que tem um livro muito bonito, na Itália tem o livro de Carla Corso e aqui saiu um livro muito interessante Montse Neira. Em todos os casos elas falam em primeira pessoa, falam de suas experiências, porque optam pelo trabalho sexual, quais são os problemas, quais são as vantagens, quais são os inconvenientes. Quando nós começamos com nosso trabalho dizíamos a elas: 'bom, agora uma vez que a organização está caminhando, o ideal é que ela funcione com vocês, sozinhas. Uma coisa é ter uma mão no começo e outra coisa é quando nos retiramos'. Mas quando elas dizem: 'não, porque não nos escutam. A nós, sozinhas, não nos escutam'. Isso para nós é triste. Eu creio que a organização que melhor tem conseguido solucionar isso é a Hetaira em Madrid. É uma sociedade mista também. Há psicólogas, sociólogas e há as trabalhadoras sexuais. Parece-me que este é um modelo perfeito. 
J.P.: Ainda na obra 'El espejo oscuro: la prostitución' (2001) argumenta sobre a construção de identidades femininas. Como o aporte teórico sobre identidades está presente em suas reflexões sobre prostituição?

D.J.: Eu creio que tem uma relação muito direta e isto se relaciona com a sociedade em que vivemos, que são sociedades patrilineares e quando nós falamos de uma sociedade patriarcal, onde, na sociedade o poder está nas mãos masculinas. Não esqueçamos que a base deste modelo patriarcal está em uma sociedade patrilinear, na qual se transmite os recursos por via masculina, o sobrenome e a filiação. Pensemos que, coisas como os exames de paternidade que pode se fazer agora, somente se pode fazer nos últimos anos. Tradicionalmente a única garantia que tinha o homem que o filho que ia receber seu sobrenome, seus recursos, sua filiação, seu prestígio, o qual continuaria a geração seguinte era realmente seu era controlar a sexualidade da mulher porque se a mulher, a mãe, teve relações sexuais com outro homem, então já não podia saber a verdadeira paternidade. $\mathrm{O}$ que estou tentando dizer é que não era um detalhe pequeno na sociedade. Julgava-se muito e o controle da sexualidade das mulheres é uma consequência desta forma de organização social. Isto é o que dá base, por outra parte a uma dupla moral. $\mathrm{O}$ homem podia fazer o que queria com sua sexualidade porque a linha de sucessão não sofria por ele. Assim, a mulher poderia ser ou deveria ser controlada. Como estamos em uma revista de Geografia me interessa sublinhar, limitando seu espaço físico, ou seja, a mulher não deve sair de casa, deve ficar em sua casa como é o modelo muçulmano. Ou ainda se deve limitar a sua liberdade interna, fazendo-a sentir-se culpada ou suja quando a mulher tem sua sexualidade fora de uma relação matrimonial. Então o estigma da prostituição, como já te disse antes, tende a defender este modelo. A mulher que não está em conformidade com o modelo esperado de boa esposa, boa mãe, boa filha, pode ser estigmatizada como prostituta e a estigmatização tem que ser muito grave para que resulte visível. É tão grave que praticamente em todas as culturas o maior insulto que se pode fazer a uma mulher é chamá-la de puta. Então, não estamos falando de certa descriminação, estamos falando da discriminação máxima, não sabemos discriminar mais que isso. Então é um tema importante.

J.P.: Por último, gostaria que comentasse como foi o início da sua carreira na Universidade de Barcelona enquanto uma mulher latinoamericana?

D.J.: Diríamos que tive sorte. Tive sorte pelo momento em que vivi. Eu cheguei a Espanha em 1977 refugiando-me da ditadura militar da Argentina. Já não podia viver na Argentina por esta circunstância, então vim para cá com minha licenciatura de Antropologia terminada e aqui tinha acabado de terminar $\mathrm{o}$ franquismo e havia uma cultura das universidades às ciências sociais. Não havia ainda faculdade de Antropologia, mas se dava antropologia como disciplina em vários cursos. Logo em seguida eu obtive a nacionalidade espanhola. Entre outras coisas pelo meu matrimônio. Mas também teria conseguido por permanência porque no momento eu estava casada com um espanhol e tinha o título de Antropologia que estava reconhecido porque havia intercâmbios entre as universidades e o reconhecimento dos títulos conseguidos na Argentina. Nestas condições quando abriu uma convocatória para cobrir cinco lugares de Antropologia eu me encontrava em boas condições porque se 
abria para uma licenciatura que ainda não existia na Espanha. Então, como não havia antropólogos espanhóis, os que davam antropologia eram historiadores, filósofos, psicólogos que tinham feito uma especialização ou um mestrado em antropologia, mas não tinham carreira completa em antropologia. Assim, não tive muitas dificuldades em entrar, cumpria todas as condições legais para entrar. Quando eu entrei o sistema universitário era contratava professores por concurso. Se não fosse por concurso eu não teria entrado, porque eu aqui não conhecia ninguém e não tinha alguém com quem eu tinha estudado, nem professores, nem ninguém que podia me dar uma mão. Este era o problema dos imigrantes, perdem todos os apoios que tem nos seus países. Depois disto eu fiz o doutorado aqui na Espanha, na universidade e apresentei a titularidade e ganhei o concurso de titularidade. Então já fiquei como professora titular até minha jubilação. Não houve barreiras digamos legais e isto seria muito diferente, por exemplo para quem vem com a licenciatura agora, da América Latina. Quem vem agora para a Espanha com uma licenciatura da América Latina vai enfrentar muita concorrência. Mas, na época do franquismo não havia nas universidades espanholas as carreiras de psicologia, sociologia, antropologia e ciências políticas. Todas estas carreiras não existiam e assim eu tive uma boa oportunidade. Em relação a língua, eu não falava Catalão. Agora posso falar, não com a mesma desenvoltura com que falo $o$ castelhano $\mathrm{e}$ a pronúncia tampouco é boa. Mas posso dizer que nunca tive nenhum problema com a língua. Esperava-se que com o tempo fosse mudando e dando aulas em catalão. Mas os alunos não demandavam. Cada vez que eu propunha dar aulas em catalão os alunos sempre diziam 'escutamos absolutamente igual. Você pode dar as aulas na língua em que sente mais cômoda'. A universidade tampouco me colocou problemas. Agora é mais difícil de todas as maneiras. $O$ que fazem na universidade é colocar no programa o idioma que as aulas serão dadas. Espera-se que os professores saibam o catalão o suficiente para que os alunos possam ser analisados em catalão, para que possam fazer os posicionamentos em classe em catalão, isto sim. Isso transforma os cursos em bilíngues. Uma coisa é que você entenda bem o que dizem em catalão e outra coisa é que o curso em catalão seja suficientemente fluido.

\section{Referências}

HERNÁNDEZ, Carmem Briz; ELIZALDE, Cristina Garaizábal e CORREGIDO, María Dolroes Juliano. La prostitución a debate: por los derechos de las prostitutas. Madrid: Talasa, 2007.

JULIANO, Dolores; CABA, Àngels; HIDALGO, Encarna; ROSET, Montserrat. Enseñar Ciencias Sociales desde valores no-androcéntricos. Madrid: Akal, 1999.

JULIANO, Dolores. Educación Intercultural: Escolarización y minorías étnicas. Madrid: EUDEMA Universidad, 1993.

JULIANO, Dolores. El espejo oscuro: la prostitución. Barcelona: Icaria, 2001.

JULIANO, Dolores. El mito del instinto maternal. Mujeres y Salud, Dossier v. 11, n. $11-12$, p. 2-5, 2003.

JULIANO, Dolores. El trabajo sexual en la mira: polemicas y estereotipos. Cadernos Pagu, n. 25, p. 79 - 106, 2005.

JULIANO, Dolores. La enseanza de las Ciencias Sociales, Geografía e Historia desde 
Mulheres especialmente marginalizadas: uma entrevista

com Dolores Juliano

un punto de vista no androcéntrico. Estado de la cuestión y líneas de avance. In: HIDALGO, Encarna; JULIANO, Dolores; ROSET, Montserrat; CABA, Àngels. (Orgs.). Repensar la enseñanza de la geografía y la historia: una mirada desde el género. Barcelona: Octaedro Ediciones, 2003, p.1871.

JULIANO, Dolores. Mujer y familia en América. In: PHILLIP, Kottak Conrad. Antropologia, una exploración de la diversidad humana. Madrid: Mac Graw Hill, 1994, p. $331-347$. 